\title{
Reduced-port surgery for rectal cancer
}

\author{
Takashi Ishida', Kohei Shigeta', Koji Okabayashi', Masashi Tsuruta', Hirotoshi Hasegawa², \\ Yuko Kitagawa ${ }^{1}$
}

\author{
'Department of Surgery, Keio University School of Medicine, Tokyo 160-8582, Japan. \\ 2Department of Surgery, Tokyo Dental College Ichikawa General Hospital, Chiba 272-8513, Japan.
}

Correspondence to: Dr. Kohei Shigeta, Department of Surgery, Keio University School of Medicine, Tokyo 160-8582, Japan. E-mail: ohlkoh@gmail.com How to cite this article: Ishida T, Shigeta K, Okabayashi K, Tsuruta M, Hasegawa H, Kitagawa Y. Reduced-port surgery for
rectal cancer. Mini-invasive Surg 2018;2:31. http://dx.doi.org/10.20517/2574-1225.2018.53

Received: 17 Jul 2018 First Decision: 20 Aug 2018 Revised: 4 Sep 2018 Accepted: 4 Sep 2018 Published: 28 Sep 2018

Science Editor: Gordon N. Buchanan Copy Editor: Cui Yu Production Editor: Zhong-Yu Guo

\begin{abstract}
Laparoscopic surgery for rectal cancer has short-term and long-term oncological outcomes similar to those of open surgery. Conventional multiport laparoscopic surgery (CMLS) for rectal cancer requires four or five abdominal incisions for trocars, each of which could lead to complications and/or pain. Single-incision laparoscopic surgery (SILS) would reduce the incidence of such wound-related complications and achieve better cosmetic outcomes relative to CMLS. The potential advantages of SILS are less pain and more rapid recovery than achieved with CMLS. However, SILS is rarely used for rectal cancer because of the high-level technical expertise required. Reduced-port laparoscopic surgery (RPS), which involves one additional port, may bridge the technical gap between CMLS and SILS and has a less steep learning curve. RPS for rectal cancer has a short history, and its usefulness has not yet been fully established. Here, we review the present situation, challenges, and future prospects for RPS for rectal cancer.
\end{abstract}

Keywords: Laparoscopic surgery, rectal cancer, reduced port surgery

\section{INTRODUCTION}

Large randomized trials [Conventional versus laparoscopic-assisted surgery in colorectal cancer (CLASICC), Clinical Outcomes of Surgical Therapy (COST), Barcelona, JCOG0404] and a meta-analysis have demonstrated that laparoscopic surgery for colon cancer is not only safe, but also associated with better short-term outcomes, with no negative effect on long-term survival ${ }^{[1-5]}$. They also revealed trends toward reduced postoperative morbidity, intraoperative blood loss, and pain, as well as faster recovery and better quality of life for laparoscopic surgery compared with open surgery ${ }^{[1,4,6-9]}$. The disadvantages were a longer

\footnotetext{
(ब) (1)

(C) The Author(s) 2018. Open Access This article is licensed under a Creative Commons Attribution 4.0 International License (https://creativecommons.org/licenses/by/4.0/), which permits unrestricted use, sharing, adaptation, distribution and reproduction in any medium or format, for any purpose, even commercially, as long as you give appropriate credit to the original author(s) and the source, provide a link to the Creative Commons license, and indicate if changes were made.
}

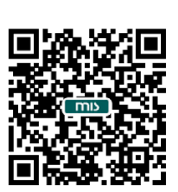


operating time, higher theater costs, and a steep learning curve. However, the long-term recurrence rate was similar and no significant difference was found in the disease-free survival (DFS) or overall survival (OS) rate ${ }^{[4]}$. Therefore, laparoscopic surgery is now considered to be an acceptable approach for colon cancer.

However, some controversy surrounds the non-inferiority of laparoscopic surgery to open surgery for rectal cancer in terms of long-term outcomes. Two previous large randomized controlled trials (RCTs), the Colorectal Cancer Laparoscopic or Open Resection (COLOR) II and Comparison of Open versus laparoscopic surgery for mid or low Rectal cancer After Neoadjuvant chemoradiotherapy (COREAN) trials, and several meta-analyses showed similar pathological and oncological outcomes of laparoscopic and open approaches for rectal cancer, and the laparoscopic approach is now a standard alternative to the open approach ${ }^{[5,10-13]}$. However, two more recent RCTs, the ALaCaRT and ACOSOG Z6051 trials, yielded contradictory results, and failed to show the non-inferiority of laparoscopic to open rectal resection ${ }^{[14,15]}$. The most recent meta-analysis showed that the risk of a positive circumferential resection margin in rectal cancer was significantly greater for laparoscopic than for open surgery ${ }^{[16]}$. Although laparoscopic surgery might be useful for the treatment of rectal cancer in selected patients, the evaluation of long-term outcomes is needed to determine whether the poor pathological outcomes have adverse effects on DFS or OS.

Laparoscopic procedures are becoming less invasive. Conventional multiport laparoscopic surgery (CMLS) for colorectal cancer (CRC) requires four or five abdominal incisions for trocars, and each incision could be associated with wound complications and pain ${ }^{[17]}$. Single-incision laparoscopic surgery (SILS) would reduce the incidence of such wound-related complications and achieve better cosmetic outcomes relative to CMLS. The potential advantages of SILS over CMLS are less pain and early recovery. Indeed, SILS reportedly has more acceptable short-term outcomes compared with $\mathrm{CMLS}^{[18-21]}$. In addition, it has been reported that SILS performed by experienced laparoscopic surgeons for selected patients can be an oncologically safe option ${ }^{[22-24]}$. However, SILS is a highly demanding procedure with several technical challenges, such as the handling of conventional laparoscopic instruments through small incisions, which could decrease the range of motion, and the potential for collisions between instruments and the camera. As a result, SILS also has disadvantages, such as a longer operation time, increased surgeon fatigue, and a steep learning curve. Reduced-port laparoscopic surgery (RPS), which is single-port surgery with one additional port, may overcome the limitations of SILS while retaining its advantages.

Here, we review the present situation, challenges, and future prospects of the use of RPS for CRC.

A comprehensive literature search was performed following an electronic search of PubMed@. Articles published in the English language between January 2013 and June 2018 were evaluated using the key terms "RPS, CRC" or "SILS, CRC". Case reports or small case series ( $<20$ cases) were excluded.

\section{CMLS, SILS, AND RPS PROCEDURES FOR RECTAL CANCER CMLS}

CMLS for CRC is usually performed via the five-port method, with an umbilical camera port, two operator ports, and two assistant ports ${ }^{[25]}$ [Figure $\left.1 \mathrm{~A}\right]$. The left colon is initially mobilized laterally to medially to the extent required for identification of the left ureter and left hypogastric nerve plexus. Mobilization of splenic flexure is performed if necessary. After intracorporeal high ligation of the inferior mesenteric vessels, mobilization of the rectum and mesorectum is performed. After mobilization of the rectum, a 3-4 cm abdominal-wall incision is made to extract the specimen. Bowel anastomosis is performed intracorporeally for anterior resection using a double-stapling technique.

\section{SILS and RPS}

A vertical $3 \mathrm{~cm}$ incision is made in the umbilicus and a multiple-instrument access port (MIAP) is placed 


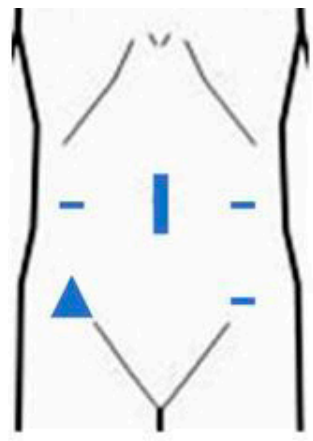

(A) CMLS

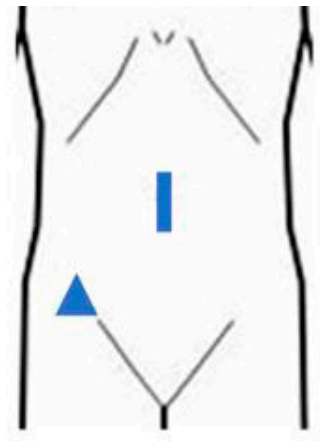

(B) RPS
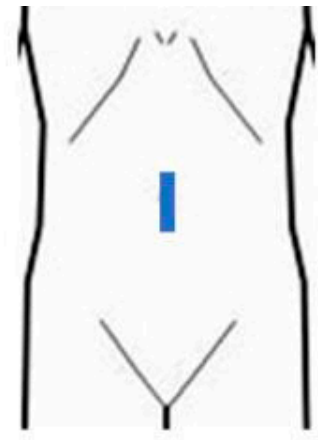

(C) SILS

Figure 1. Trocars placement in conventional (A), reduced port (B) and single incision (C) laparoscopic surgery for rectal cancer

at the site ${ }^{[26]}$. SILS is performed entirely through this access port ${ }^{[27]}$. For RPS, an additional port is inserted on the operator's dominant-hand side [Figure 1A and C]. The assistant uses one channel of the MIAP to create a working view, and a $5 \mathrm{~mm}$ flexible-tip laparoscope is inserted through the other MIAP channel. A flexible laparoscope is useful for preventing interference from the hand instruments. After mobilization of the rectum, the transumbilical site is used to extract the specimen, and bowel anastomosis is performed in the same manner as in CMLS.

\section{SILS compared with CMLS}

Although no RCT on the subject has been performed, the most recent systematic review showed that colorectal SILS is at least as feasible and safe as CMLS in selected patients with rectal cancer ${ }^{[17]}$. SILS had outcomes comparable to those of CMLS in terms of operating time, conversion rate, reoperation rate, postoperative complication rate, and mortality rate. The oncological results of SILS for CRC were satisfactory, as demonstrated by similar average lymph-node retrieval and adequate resection margins relative to those obtained with CMLS. Nevertheless, long-term follow-up data on survival and local recurrence rates are lacking. In addition, colorectal SILS is technically limited because of instrument crowding, in-line viewing, and insufficient countertraction ${ }^{[24,28]}$. In particular, cutting of the distal rectum from the umbilicus using a linear stapler is technically difficult ${ }^{[29]}$. Therefore, the authors of the systemic review concluded that they could not recommend the use of SILS instead of CMLS for CRC ${ }^{[17]}$.

\section{RPS compared with CMLS}

RPS has become more feasible due to the accumulation of experience and improvement of laparoscopic tools, such as energy devices and specific forceps. Although they included relatively few patients with rectal cancer, four retrospective studies have compared RPS with CMLS for the treatment of this disease $\mathrm{e}^{[27,30-32]}$. The advantages of RPS over CMLS are summarized in Table 1. No RCT, systematic review, or metaanalysis has compared the outcomes of RPS and CMLS. An RCT of the short-term surgical and long-term oncological safety of RPS compared with CMLS for rectosigmoid colon cancer is underway ${ }^{[33]}$.

One study evaluated long-term oncological outcomes after RPS for rectosigmoid cancer. Liu et al. ${ }^{[27]}$ reported that the 3-year DFS and OS rates were comparable between the RPS and CMLS groups.

Regarding short-term outcomes, the operation time is shorter for RPS than for CMLS ${ }^{[27,30,31]}$, possibly due to selection bias ${ }^{[30,31]}$ or a decreased time to wound closure as a result of the fewer and smaller wounds created during $\operatorname{RPS}^{[30]}$.

RPS is less invasive than CMLS and results in shorter times to flatus passage, liquid diet consumption, and 
Table 1. Retrospective studies comparing reduced port laparoscopic surgery and conventional multiport laparoscopic surgery (CMLS) for colorectal cancer (CRC)

\begin{tabular}{|c|c|c|c|c|c|c|}
\hline Author & Publication year & Reference & $\begin{array}{l}\text { Total patients included } \\
\text { (RPS vs. CMLS) }\end{array}$ & Accrual & Difference seen in RPS & \\
\hline \multirow[t]{2}{*}{ Kang et al. } & 2018 & 31 & 73 vs. 111 & $2011-2017$ & Operation time & Shorter \\
\hline & & & & & Gas passage time & Longer \\
\hline \multirow[t]{4}{*}{ Song et al. } & 2016 & 32 & 32 vs. $217^{\star}$ & $2011-2013$ & Operation time & Shorter \\
\hline & & & & & Blood loss & Less \\
\hline & & & & & Gas passage time & Shorter \\
\hline & & & & & Pain & Less \\
\hline \multirow[t]{10}{*}{ Liu et al. } & 2017 & 27 & 48 vs. $48^{\star \star}$ & $2011-2014$ & $3 Y$ DFS & N.S. \\
\hline & & & & & $3 Y$ OS & N.S. \\
\hline & & & & & Operation time & Shorter \\
\hline & & & & & Total incision length & Shorter \\
\hline & & & & & Time to liquid diet & Shorter \\
\hline & & & & & Time to ambulation & Shorter \\
\hline & & & & & Discharge & Less \\
\hline & & & & & Pain & Less \\
\hline & & & & & $\begin{array}{l}\text { Postoperative CRP and } \\
\text { IL-6 levels }\end{array}$ & Lower \\
\hline & & & & & Cosmesis & Better \\
\hline \multirow[t]{3}{*}{ Kawamata et al. } & 2014 & 33 & 20 vs. 20 & 2010-2012 & Operation time & N.S. \\
\hline & & & & & $\begin{array}{l}\text { Postoperative neutrophil } \\
\text { counts }\end{array}$ & Lower \\
\hline & & & & & $\begin{array}{l}\text { Postoperative body } \\
\text { temparature }\end{array}$ & Lower \\
\hline
\end{tabular}

RPS: Reduced-port laparoscopic surgery

ambulation $^{[27,31]}$. In addition, RPS leads to less postoperative pain and better cosmetic results than does CMLS because of the shorter total incision length ${ }^{[27,31]}$. Therefore, patients who undergo RPS have better postoperative outcomes. However, the estimated blood loss, morbidity rate, conversion rate, and number of harvested lymph nodes were comparable, suggesting that RPS is a feasible and safe procedure in the early postoperative stage ${ }^{[27,30]}$. Furthermore, the postoperative neutrophil count, C-reactive protein level, interleukin- 6 level, and body temperature were significantly lower after RPS compared with CMLS ${ }^{[27,32]}$, which may accelerate recovery. Another advantage of RPS may be its cost effectiveness. The instrument cost for RPS may be lower due to the reduced number of trocars required; however, previous studies have not evaluated this factor. A shortened hospital stay and decreased analgesic use may also reduce the $\operatorname{cost}^{[34,35]}$.

A MIAP can be placed at the ileostomy site and the excised specimen can be brought out during a reduced port laparoscopic low anterior resection with diverting ileostomy. Furthermore, a drainage tube can be placed via the additional port ${ }^{[36]}$. The use of MIAP as the ileostomy site represents a minimally invasive approach that results in a scarless procedure.

\section{Superiority of RPS over SILS}

RPS for CRC may have several advantages over CMLS. Since Burcher et al. ${ }^{[37]}$ performed the first SILS for colorectal diseases, it has become widely used because of technical advancements. However, SILS has a risk of collisions between instruments and is limited by use of triangular tissue traction ${ }^{[21,24,38]}$; consequently, SILS is used infrequently worldwide ${ }^{[36]}$. In contrast, the additional port created during RPS reduces the risk of collision between surgical instruments and the laparoscope, as well as shortening the operation time compared with SILS ${ }^{[27]}$. Therefore, RPS involves fewer technical difficulties than does SILS. Moreover, RPS has other advantages over SILS, such as the convenience of an intracorporeal suture and stable drain placement via the additional port. 

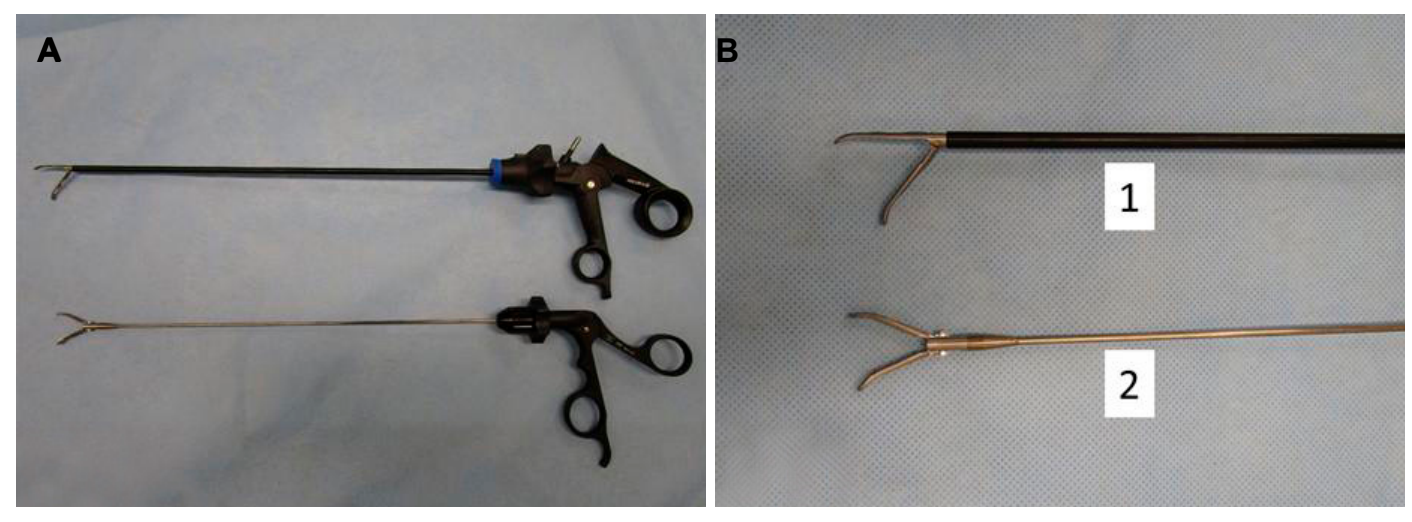

Figure 2. (A): Gross view of the instruments used in needlescopic surgery; (B): close up of the tips of the instruments shown in (A); 1 : conventional $5 \mathrm{~mm}$ forceps; 2: same-sized tip section as that of the $5 \mathrm{~mm}$ forceps with a $2.4 \mathrm{~mm}$-diameter shaft

SILS was initially expected to result in less postoperative pain compared with CMLS. However, this argument is controversial; indeed, the degree of postoperative pain after SILS is reportedly similar to or greater than that following CMLS $^{[39-41]}$. Although SILS involves fewer incision sites, the single incision could be lengthened and stretched by insertion of a single port due to the challenges of handling conventional laparoscopic instruments ${ }^{[27]}$. This factor might explain the postoperative pain after SILS. The advantages of RPS are a reduced level of technical difficulty and cosmetic outcomes similar to those of SILS, and an operation time comparable to that of CMLS. In addition, the lengthening and stretching of the single incision are reduced during RPS relative to SILS, which may decrease postoperative pain. The results of a large prospective RCT comparing RPS with CMLS are awaited ${ }^{[33]}$.

\section{Future perspectives}

RPS may be superior to SILS for CRC, as it has a lower level of technical difficulty while maintaining less invasiveness. However, RPS is typically performed by a single surgeon and a laparoscopist, and has a steep learning curve because the reduced number of ports interferes with forceps mobilization, leading to less effective countertraction and visualization. Therefore, RPS may still be difficult to perform for less experienced surgeons.

To overcome this difficulty, needlescopic surgery, which involves the use of forceps with a small-diameter shaft instead of the conventional $5 \mathrm{~mm}$ port, has been developed ${ }^{[42]}$ [Figure 2]. Although the feasibility of needlescopic surgery compared with CMLS for CRC has been evaluated ${ }^{[43,44]}$, needlescopic surgery is expected to be less invasive and produce better cosmetic outcomes than CMLS. In addition, needlescopic surgery for CRC does not increase surgeon stress, as it is basically identical to CMLS for all surgical procedures. The disadvantages of the use of a small-diameter shaft in needlescopic surgery are the low shaft stiffness and inability to exchange instruments ${ }^{[42]}$. However, the stiffness and operability of these tools have gradually been improved.

Although further prospective randomized studies of RPS (including needlescopic surgery) compared with CMLS for CRC are required, needlescopic surgery for CRC may be a good starting point for young surgeons and make feasible even less-invasive surgery.

\section{CONCLUSION}

Although further investigation is required, the surgical and oncological outcomes of SILS and RPS suggest that they are safe and feasible procedures. RPS may be superior to SILS due to its lower level of technical 
difficulty while maintaining less invasiveness.

\section{DECLARATIONS}

\section{Author's contributions}

Design, manuscript writing: Shigeta K, Ishida T

Literature research, data analysis: Ishida $\mathrm{T}$

Manuscript editing: Okabayashi K, Tsuruta M, Hasegawa H, Kitagawa Y

\section{Availability of data and materials}

Not applicable.

\section{Financial support and sponsorship}

None.

\section{Conflicts of interest}

All authors declared that there were no conflicts of interest.

\section{Ethical approval and consent to participate}

Not applicable.

\section{Consent for publication}

Not applicable.

\section{Copyright}

(c) The Author(s) 2018.

\section{REFERENCES}

1. Guillou PJ, Quirke P, Thorpe H, Walker J, Jayne DG, Smith AM, Heath RM, Brown JM; MRC CLASICC trial group. Short-term endpoints of conventional versus laparoscopic-assisted surgery in patients with colorectal cancer (MRC CLASICC trial): multicentre, randomised controlled trial. Lancet 2005;365:1718-26.

2. Clinical Outcomes of Surgical Therapy Study Group, Nelson H, Sargent DJ, Wieand HS, Fleshman J, Anvari M, Stryker SJ, Beart RW Jr, Hellinger M, Flanagan R Jr, Peters W, Ota D. A comparison of laparoscopically assisted and open colectomy for colon cancer. N Engl J Med 2004;350:2050-9.

3. Lacy AM, García-Valdecasas JC, Delgado S, Castells A, Taurá P, Piqué JM, Visa J. Laparoscopy-assisted colectomy versus open colectomy for treatment of non-metastatic colon cancer: a randomised trial. Lancet 2002;359:2224-9.

4. Kitano S, Inomata M, Mizusawa J, Katayama H, Watanabe M, Yamamoto S, Ito M, Saito S, Fujii S, Konishi F, Saida Y, Hasegawa H, Akagi T, Sugihara K, Yamaguchi T, Masaki T, Fukunaga Y, Murata K, Okajima M, Moriya Y, Shimada Y. Survival outcomes following laparoscopic versus open D3 dissection for stage II or III colon cancer (JCOG0404): a phase 3, randomised controlled trial. Lancet Gastroenterol Hepatol 2017;2:261-8.

5. Bonjer HJ, Deijen CL, Abis GA, Cuesta MA, van der Pas MH, de Lange-de Klerk ES, Lacy AM, Bemelman WA, Andersson J, Angenete E, Rosenberg J, Fuerst A, Haglind E; COLOR II Study Group. A randomized trial of laparoscopic versus open surgery for rectal cancer. N Engl J Med 2015;372:1324-32.

6. Lacy AM, García-Valdecasas JC, Piqué JM, Delgado S, Campo E, Bordas JM, Taurá P, Grande L, Fuster J, Pacheco JL, Visa J. Shortterm outcome analysis of a randomized study comparing laparoscopic vs open colectomy for colon cancer. Surg Endosc 1995;9:1101-5.

7. Biondi A, Grosso G, Mistretta A, Marventano S, Toscano C, Gruttadauria S, Basile F. Laparoscopic-assisted versus open surgery for colorectal cancer: short- and long-term outcomes comparison. J Laparoendosc Adv Surg Tech A 2013;23:1-7.

8. Braga M, Vignali A, Gianotti L, Zuliani W, Radaelli G, Gruarin P, Dellabona P, Di Carlo V. Laparoscopic versus open colorectal surgery: a randomized trial on short-term outcome. Ann Surg 2002;236:759-66.

9. Weeks JC, Nelson H, Gelber S, Sargent D, Schroeder G; Clinical Outcomes of Surgical Therapy (COST) Study Group. Short-term quality-of-life outcomes following laparoscopic-assisted colectomy vs open colectomy for colon cancer: a randomized trial. JAMA 2002;287:321-8.

10. Jeong SY, Park JW, Nam BH, Kim S, Kang SB, Lim SB, Choi HS, Kim DW, Chang HJ, Kim DY, Jung KH, Kim TY, Kang GH, Chie EK, Kim SY, Sohn DK, Kim DH, Kim JS, Lee HS, Kim JH, Oh JH. Open versus laparoscopic surgery for mid-rectal or lowrectal cancer after neoadjuvant chemoradiotherapy (COREAN trial): survival outcomes of an open-label, non-inferiority, randomised controlled trial. Lancet Oncol 2014;15:767-74. 
11. van der Pas MH, Haglind E, Cuesta MA, Fürst A, Lacy AM, Hop WC, Bonjer HJ; COlorectal cancer Laparoscopic or Open Resection II (COLOR II) Study Group. Laparoscopic versus open surgery for rectal cancer (COLOR II): short-term outcomes of a randomised, phase 3 trial. Lancet Oncol 2013;14:210-8.

12. Kang SB, Park JW, Jeong SY, Nam BH, Choi HS, Kim DW, Lim SB, Lee TG, Kim DY, Kim JS, Chang HJ, Lee HS, Kim SY, Jung $\mathrm{KH}$, Hong YS, Kim JH, Sohn DK, Kim DH, Oh JH. Open versus laparoscopic surgery for mid or low rectal cancer after neoadjuvant chemoradiotherapy (COREAN trial): short-term outcomes of an open-label randomised controlled trial. Lancet Oncol 2010;11:637-45.

13. Hida K, Okamura R, Sakai Y, Konishi T, Akagi T, Yamaguchi T, Akiyoshi T, Fukuda M, Yamamoto S, Yamamoto M, Nishigori T, Kawada K, Hasegawa S, Morita S, Watanabe M; Japan Society of Laparoscopic Colorectal Surgery. Open versus laparoscopic surgery for advanced low rectal cancer: a large, multicenter, propensity score matched cohort study in Japan. Ann Surg 2018;268:318-24.

14. Fleshman J, Branda M, Sargent DJ, Boller AM, George V, Abbas M, Peters WR Jr, Maun D, Chang G, Herline A, Fichera A, Mutch M, Wexner S, Whiteford M, Marks J, Birnbaum E, Margolin D, Larson D, Marcello P, Posner M, Read T, Monson J, Wren SM, Pisters PW, Nelson H. Effect of laparoscopic-assisted resection vs open resection of stage II or III rectal cancer on pathologic outcomes: the ACOSOG Z6051 randomized clinical trial. JAMA 2015;314:1346-55.

15. Stevenson AR, Solomon MJ, Lumley JW, Hewett P, Clouston AD, Gebski VJ, Davies L, Wilson K, Hague W, Simes J; ALaCaRT Investigators. Effect of laparoscopic-assisted resection vs open resection on pathological outcomes in rectal cancer: the ALaCaRT randomized clinical trial. JAMA 2015;314:1356-63.

16. Martínez-Pérez A, Carra MC, Brunetti F, de’Angelis N. Pathologic outcomes of laparoscopic vs open mesorectal excision for rectal cancer: a systematic review and meta-analysis. JAMA Surg 2017;152:e165665.

17. Hoyuela C, Juvany M, Carvajal F. Single-incision laparoscopy versus standard laparoscopy for colorectal surgery: a systematic review and meta-analysis. Am J Surg 2017;214:127-40.

18. Kim SJ, Ryu GO, Choi BJ, Kim JG, Lee KJ, Lee SC, Oh ST. The short-term outcomes of conventional and single-port laparoscopic surgery for colorectal cancer. Ann Surg 2011;254:933-40.

19. Egi H, Hattori M, Hinoi T, Takakura Y, Kawaguchi Y, Shimomura M, Tokunaga M, Adachi T, Urushihara T, Itamoto T, Ohdan H. Single-port laparoscopic colectomy versus conventional laparoscopic colectomy for colon cancer: a comparison of surgical results. World J Surg Oncol 2012;10:61.

20. Papaconstantinou HT, Thomas JS. Single-incision laparoscopic colectomy for cancer: assessment of oncologic resection and short-term outcomes in a case-matched comparison with standard laparoscopy. Surgery 2011;150:820-7.

21. Poon JT, Cheung CW, Fan JK, Lo OS, Law WL. Single-incision versus conventional laparoscopic colectomy for colonic neoplasm: a randomized, controlled trial. Surg Endosc 2012;26:2729-34.

22. Kim CW, Cho MS, Baek SJ, Hur H, Min BS, Kang J, Baik SH, Lee KY, Kim NK. Oncologic outcomes of single-incision versus conventional laparoscopic anterior resection for sigmoid colon cancer: a propensity-score matching analysis. Ann Surg Oncol 2015;22:924-30.

23. Yun JA, Yun SH, Park YA, Huh JW, Cho YB, Kim HC, Lee WY. Oncologic outcomes of single-incision laparoscopic surgery compared with conventional laparoscopy for colon cancer. Ann Surg 2016;263:973-8.

24. Katsuno G, Fukunaga M, Nagakari K, Yoshikawa S, Azuma D, Kohama S. Short-term and long-term outcomes of single-incision versus multi-incision laparoscopic resection for colorectal cancer: a propensity-score-matched analysis of 214 cases. Surg Endosc 2016;30:1317-25.

25. Yamamoto S, Watanabe M, Hasegawa H, Kitajima M. Prospective evaluation of laparoscopic surgery for rectosigmoidal and rectal carcinoma. Dis Colon Rectum 2002;45:1648-54.

26. Ishii Y, Hasegawa H, Endo T, Ochiai H, Okabayashi K, Kitagawa Y. Reduced-port laparoscopic surgery for rectal cancer: feasibility based on our early experience. Asian J Endosc Surg 2013;6:249-52.

27. Liu R, Wang Y, Zhang Z, Li T, Liu H, Zhao L, Deng H, Li G. Assessment of treatment options for rectosigmoid cancer: singleincision plus one port laparoscopic surgery, single-incision laparoscopic surgery, and conventional laparoscopic surgery. Surg Endosc 2017;31:2437-50.

28. Takemasa I, Uemura M, Nishimura J, Mizushima T, Yamamoto H, Ikeda M, Sekimoto M, Doki Y, Mori M. Feasibility of singlesite laparoscopic colectomy with complete mesocolic excision for colon cancer: a prospective case-control comparison. Surg Endosc 2014;28:1110-8.

29. Watanabe J, Ota M, Suwa Y, Ishibe A, Masui H, Nagahori K. Single-incision laparoscopic anterior resection using a curved stapler. Dis Colon Rectum 2016;59:1105-9.

30. Kang JH, Lee SY, Kim CH, Kim HR, Kwak HD, Ju JK, Kim YJ. Comparison of the short-term outcomes of reduced-port laparoscopic surgery and conventional multiport surgery in colon cancer: a propensity score matching analysis. Ann Surg Treat Res 2018;94:147-53.

31. Song JM, Kim JH, Lee YS, Kim HY, Lee IK, Oh ST, Kim JG. Reduced port laparoscopic surgery for colon cancer is safe and feasible in terms of short-term outcomes: comparative study with conventional multiport laparoscopic surgery. Ann Surg Treat Res 2016;91:195201.

32. Kawamata F, Homma S, Minagawa N, Kawamura H, Takahashi N, Taketomi A. Comparison of single-incision plus one additional port laparoscopy-assisted anterior resection with conventional laparoscopy-assisted anterior resection for rectal cancer. World J Surg 2014;38:2716-23.

33. Wang Y, Liu R, Zhang Z, Xue Q, Yan J, Yu J, Liu H, Zhao L, Mou T, Deng H, Li G. A safety study of transumbilical single incision versus conventional laparoscopic surgery for colorectal cancer: study protocol for a randomized controlled trial. Trials 2015;16:539.

34. Chambers WM, Bicsak M, Lamparelli M, Dixon AR. Single-incision laparoscopic surgery (SILS) in complex colorectal surgery: a technique offering potential and not just cosmesis. Colorectal Dis 2011;13:393-8.

35. Gash KJ, Goede AC, Chambers W, Greenslade GL, Dixon AR. Laparoendoscopic single-site surgery is feasible in complex colorectal resections and could enable day case colectomy. Surg Endosc 2011;25:835-40. 
36. Yu H, Shin JY. Short-term outcomes following reduced-port, single-port, and multi-port laparoscopic surgery for colon cancer: tailored laparoscopic approaches based on tumor size and nodal status. Int J Colorectal Dis 2016;31:115-22.

37. Bucher P, Pugin F, Morel P. Single port access laparoscopic right hemicolectomy. Int J Colorectal Dis 2008;23:1013-6.

38. Choi SI, Lee KY, Park SJ, Lee SH. Single port laparoscopic right hemicolectomy with D3 dissection for advanced colon cancer. World J Gastroenterol 2010;16:275-8.

39. Wolthuis AM, Penninckx F, Fieuws S, D'Hoore A. Outcomes for case-matched single-port colectomy are comparable with conventional laparoscopic colectomy. Colorectal Dis 2012;14:634-41.

40. Kim SJ, Choi BJ, Lee SC. Successful total shift from multiport to single-port laparoscopic surgery in low anterior resection of colorectal cancer. Surg Endosc 2014;28:2920-30.

41. Park SJ, Lee KY, Kang BM, Choi SI, Lee SH. Initial experience of single-port laparoscopic surgery for sigmoid colon cancer. World J Surg 2013;37:652-6.

42. Mukai T, Fukunaga Y, Ueno M, Nagayama S, Fujimoto Y, Konishi T, Akiyoshi T, Ono R, Yamaguchi T. Needlescopic surgery for leftsided colorectal cancer. Int J Colorectal Dis 2014;29:1501-5.

43. Nakanishi M, Kuriu Y, Murayama Y, Arita T, Ito H, Kosuga T, Morimura R, Konishi H, Komatsu S, Shiozaki A, Ikoma H, Ichikawa D, Fujiwara H, Okamoto K, Otsuji E. Usefulness of reduced port surgery for left colon cancer. Anticancer Res 2016;36:4749-52.

44. Tsuruta M, Hasegawa H, Okabayashi K, Shigeta K, Ishida T, Yahagi M, Ishii Y, Kitagawa Y. Needlescopic versus conventional laparoscopic surgery for colorectal cancer a comparative study . J Anus Rectum Colon 2017;1:45-49. 